\title{
Features of representative design for academic needs - development of conceptual models when designing symbols and regalia
}

\author{
Hristina Vasileva Tacheva ${ }^{1}$ \\ 1 - Technical University of Varna, Department Industrial Design, 9010, 1 Studentska Street, Varna, Bulgaria \\ Corresponding author contact: hriz@abv.bg
}

\begin{abstract}
Authority symbols play a significant role in building the internal structure and representative function in the various governmental organizations and in particular - high schools and universities. There is a growing need of creating and implementing a clear methodology for designing academic signs based on a thorough analysis of principles in the design of the academic regalia in a real high school.
\end{abstract}

Keywords: academic signs, design, methodology, universities, regalia, representative function

\section{Introduction}

Authority symbols play a significant role in building the internal structure (hierarchy) in the various organizations/ countries, universities, non-governmental associations, etc. As society evolves and evolves, more and more public and private entities are emerging and need signs that distinguish them from others. Although most high education institutions in the country are institutions with a rich history, the need to work purposefully to address the issue of inconsistency and the lack of categorical traditions in the design of academic signs, symbols and regalia is increasingly emphasized. The need to integrate and standardize academic regalia and design them through certain approaches and methods is tangible.

\section{Argumentation}

Last years, in certain institutions are noticed trends for searching more comprehensive concepts, theoretical channelling of advertising and representative accessories and signs. As examples of possible ways for addressing the problem of identity and tradition through design methods, some of our own concepts applied to PR campaigns and institutional regalia of the Medical University of Varna can serve.

In search of solutions for this problem the following research and analysis points stood out:

- Reviewing examples of the historical development and significance of the authority symbols worldwide;

- Analysis of certain examples of similar symbols and distinctions in Bulgaria and other countries;

- Analysis of modern technologies and materials used in designing signs, symbols and regalia for academic purposes;

- Expanding the registry by introducing new subjects with a representative function to the main attributes;

- A suggestion for options and methodology to reach the target;

- Practical solution of the problem - presentation of author's works on the topic with application in modern academic practice in Bulgaria; 


\section{Terminological device}

„Design, defined in the broadest sense as conceptand design of man-made products, can be seen as a means of improving the quality of life ". (Charlotte and Fiel, 2001 ) From here comes one of its main directions - representative designs. Here comes one of its main directions - the representative design. The idea of modern design "Creating works that combine intellectual, practical, commercial and aesthetic creative pursuits through artistic means and the use of new technologies" (Charlotte and Fiel, 2001) is fully embedded in it. Various interpretations are found in literature, but in direct significance the representative design includes - objects bearing the symbols and signs of certain organizations, universities arousing respect with appearance and with possible additional influence (advertising, informative, popularizing function, etc.)As a consequence of the main characteristics of the representative design for academic purposes, the necessity and the perception of an extended register of such objects should be analysed and not only the essential Rector regalia (necklace, rod, gown). With the development of technology and the daily enrichment of academic history, gradually through design development in academic symbolism additional objects / plaques, awarding signs, prizes/, bearing the symbolism, solemnity and PR messages are set at the core without which university rituals and ceremonies are inconceivable. This whole new wave of accessories and items, require an overall, unified approach in designing, yet it should be intriguing and spectacular. However, in the process of an analysis and standardization, it is necessary to answer important questions such as: Do we have to literally take on the Western models and approaches in building a methodology of symbols in Bulgaria, also to what extent to integrate elements, showing our national identity. Establishing methodology and standardization into a representative design for academic purposes leads to an increase in authority, reflection of certain spiritual values, knowledge and professional competencies. Thus each high education institution acquires wide publicity, transparency and identity with the interests of contemporary civil society. When Designing these objects, to follow the principles of corporate design is not enough. The solution to problems in designing academic design objects requires a subtle sense of balance between aesthetics, functionality and tradition. At the same time, a clear categorization of academic regalia and objects from the representative design is needed. For illustration in this context, the present study will use examples - author's proffers and developments for the extended range of basic and additional subjects, accepted and applied for the specifics and needs of the Medical University Varna.

\section{Establishment and appearance of the first university symbols, traditions and regalia}

\subsection{Regalia of academic management and hierarchy.}

4.1.1. The gown (fig. 1) is the traditional clothing of the Roman at the earliest times. The earliest images are on sculptures dating back to the 3rd century BC. Heavy with sophisticated draperies, the gown implies that the one dressed in it should be indulged to oratory. Along with the Latin language, the gown is perceived in the early classical academic symbol to remain in it forever.

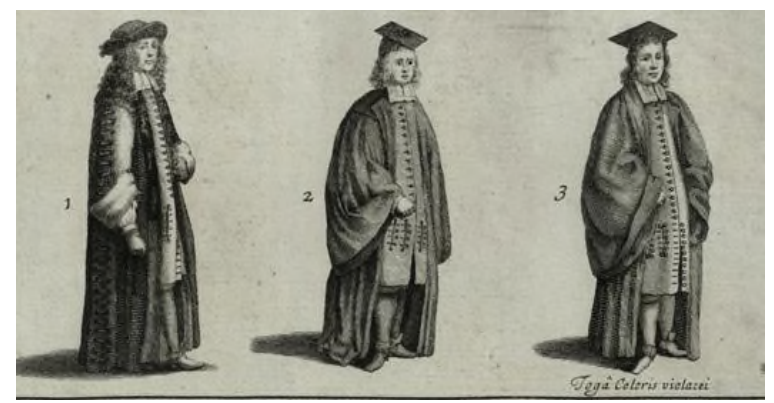

Fig. 1 Examples for academic clothing's ${ }^{1}$ 
The obtaining of an academic degree during XI - XII century in Europe, passes through the same stages as in the craftsman's guilds (where the degrees are also three - an apprentice, a journeyman and a master) - i.e. after the passing of these stages the finished person could start to teach other people. The different classes have decorated the overcoat in a different way. The elegance has depended on the rank and wealth. At the same time (XIV - XV century) has appeared the hood, which has endured even bigger modifications in order to be reached to a separate hat and a hood. After XVI century a hood was worn only by clergymen and academic persons, as an element in the clothing, emphasizing the degree of the academic person or the rank of the spiritual. The academic clothing should be worn in the presence of the Rector and the Deputy-rector at the exams of the University, as well as on formal meetings.

In the course of time to the clothings were added additional accessories as tassels and scarfs, which distinguish the separate schools and universities or emphasize the rank of the person, who is wearing them. Gradually they have been perceived and acknowledged as personable elements of the regalia. In the contemporaneity there is a large selection of colours and additional elements in the clothing and hat. In fact the colours, brightness and magnificence of the academic clothing add particular solemnity and official shade of the event, on which they are worn.

The historical roots of the academic clothing bear and longer a symbolical meaning about the boundlessness of the knowledge in the universe, about the eternal values, which the students should follow and about the strength of the personal faith, freedom and tolerance towards the outlooks of the separate individual. These fundamentals of the academic freedom have been operating in Great Britain for the last three hundred years and they shall continue to be enforced in the future years.

One of the main tasks of the formal academic clothing is to be sufficiently distinguishable in order to be connected with a concrete school or university. In fact the colours, brightness and magnificence of the academic clothing add peculiar solemnity and formal shade of the event, on which they are worn.

4.1.1.1. The Rector's toga (fig. 2) at Medical University-Varna was renewed in year 2012. A completely new cut and colours were selected, reflecting the contemporary tendencies. It has been sewed out of red heavy silk fabric, with sewed on black velvet fabric along its length, representing the academic scarf, edged by a golden gallon. The particular colour was not chosen in vain,, Червеното е силен цвят, свързан с виталността. То е силно и привличащо “. ( Чин, 2007 ). On each sleeve on the toga, there are put four velvet elements with the same gallon, representing the degree and the title of the person, who is wearing the toga. In contrast to its predecessor the present toga is closed by a zip, which impedes its displacement. On the black scarf is embroidered the emblem of the university.
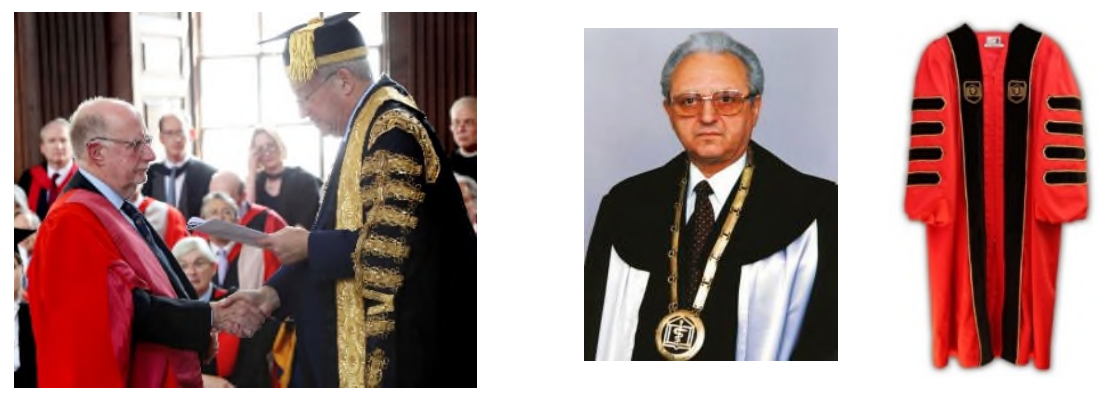

Fig. 2 Rector's toga from the University of Cambridge. Previous and modernized Rector's toga from Medical University-Varna ${ }^{2}$

\footnotetext{
${ }^{2}$ Rector's toga from the University of Cambridge. Previous and modernized Rector's togafromMedical University-Varna ${ }^{2}$ https://www.cam.ac.uk and personal archive (2017)
} 
4.1.1.2. The Dean's toga (fig. 3) is identical in cut and stripes to the Rector's toga. It shows the different statute through its colour, the number of its stripes and edges. In contrast to the red crimson at the Rector, the Dean's toga is in navy blue colour with red edges. The stripes are less in number, and the edges along the length and the sleeves are in grey colour. The length of each toga is strictly conformed to the distance from the base of the heel to the middle of the shank.

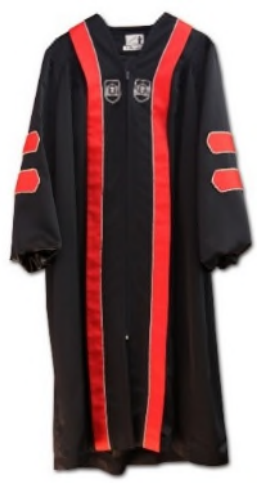

Fig. 3 Modernized Dean's toga from Medical University-Varna ${ }^{3}$

4.1.1.3. Student toga. Besides the representatives of the academic leaders, the toga is used for a formal costume and at the promotions and handing in of the diplomas of the graduated students. The symbols of the graduation dignity are worn during the time of the ceremonies for handing in of the diplomas of the graduating students. Their costume is more simplified, but additional elements are used.

The hat is an important component of the basic academic costume. It can demonstrate also the academic degree of its owner or to bring information about the respective academic institution.

The tassel is predominantly black as at the same time to it can be added the colours of the university, the colours of a specific college or discipline. The tassels have also been used in order to be indicated membership in different national communities.

4.1.2 The necklace symbolizes high official status and dignity, but also obligations, which the respective post imposes. It has entered in the university symbolization from the church, monarchical and aristocratic Medieval-Renaissance hierarchy and has transformed into an obligatory attribute of the Rector's dignity.

4.1.2.1 Rector's necklace (fig. 4). It is designed using graphical design techniques, representing "synthesis of the most important information, more appropriate, depending on the target group to which the product is targeted"4.At the conception for the Rector's necklace for a base has been chosen the concentric shape, which consists of two inter-woven hexagons, which symbolize the eternity of the scientific knowledge. The whole medallion is elaborated out of bronze. At the center of the medallion is engraved the logo of Medical University - Varna out of bronze: an opened book in the temple of knowledge with center the medical emblem - a staff with a snake wound around it. The base of the medallion is elaborated out of blue stone. "Blue is a cool and calming colour that shows creativity and intelligence. It is a colour that symbolizes loyalty, strength, wisdom and trust." ${ }^{5} \mathrm{He}$ is $\mathrm{b}$ a basic principles in the medical education and in the doctor's profession. The separate rings of the chain are semiotically

${ }^{3}$ Modernized Dean's togafromMedical University-Varna ${ }^{3}$ Personal archive ${ }^{4}$ http://igcbg.com/ (2017)

${ }^{5} \mathrm{https}$ //www.color-meanings.com/blue-color-meaning-the-color-blue/ (2017) 
loaded through the idea about the Solomon's knots, as embodiment of wisdom and knowledge as a whole. It is extremely important to review the checklist for submitting files to the subcontractor ( Лольр, 2006 ).

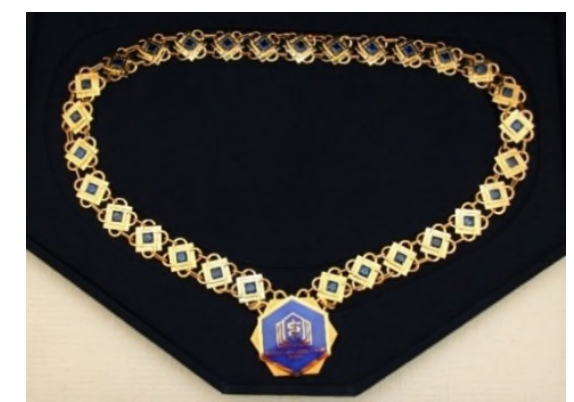

Fig. 4 Updated Rector's necklace from Medical University-Varna ${ }^{6}$

4.1.2.2. The Dean's necklace (fig. 5) repeats the basic forms of the Rector's one, but it emphasizes on the statute through its silver-plated colour, hemstitchness and the additional plasticity of the Solomon's knots, which are forming the necklace.

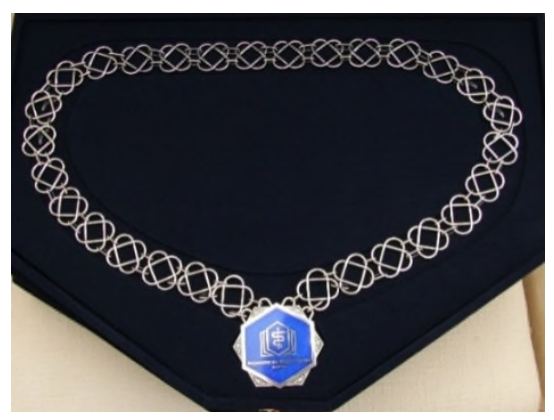

Fig. 5 Updated Dean's necklace from Medical University-Varna ${ }^{7}$

4.1.3. In almost all cultural traditions the mace (fig. 6) is an attribute which embodies the male beginning, the power, might and authority. At the academic ceremonial the mace is carried in front of the rector as a symbol of the Rector's dignity and authority.
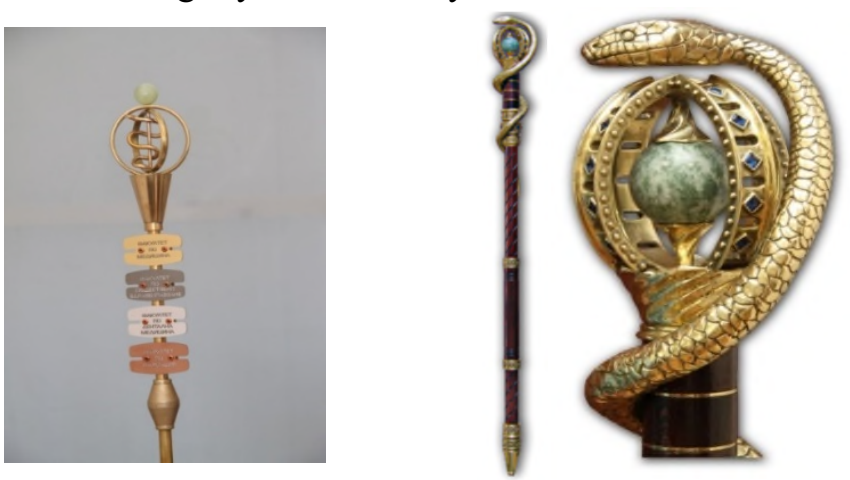

Fig. 6 Previous and modernized Rector's mace from Medical University-Varna ${ }^{8}$

\footnotetext{
${ }^{6}$ Updated Rector's necklace from Medical University-Varna ${ }^{6}$ Personal archive

${ }^{7}$ Updated Dean's necklace from Medical University- Varna ${ }^{7}$ Personal archive

${ }^{8}$ Previous and modernized Rector's macefromMedical University-Varna ${ }^{8}$ Personal archive
} 
The flag (fig. 7) is also an important symbol in the academic tradition. The flag of the Medical university - Varna is elaborated out of white silk and tinsel. In conformity with the heraldic tradition on the white background are embroidered the emblem and the name of the institution in blue: Medical university "Prof. Dr. Paraskev Stoyanov". The purpose of the laconic approach is the logo to be maximum readable and distinguishable. The flag is carried in formal and particularly solemn cases. It is necessary for the color printing of the machines to be of high color fidelity to the submitted project ( Лольр, 2006 ).
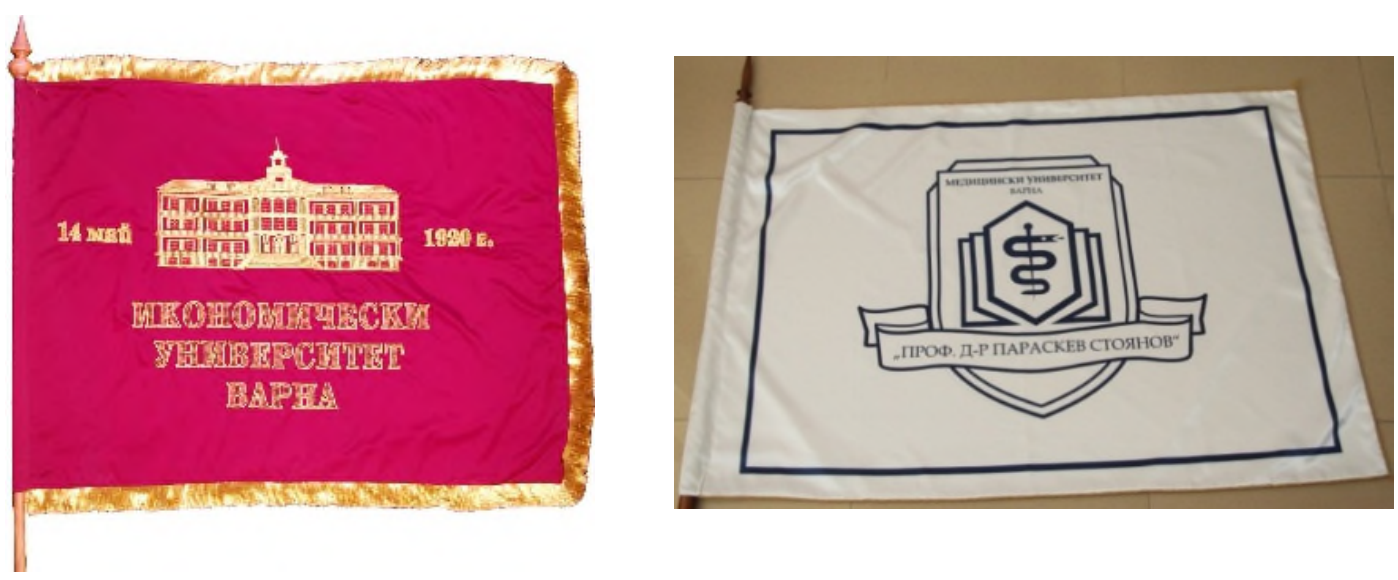

Fig. 7 Official flag from University of Economics - Varna and Medical University-Varna ${ }^{9}$

Because of the necessity of maximum full value and adequate representation of the university in front of the rest community, there are elaborated variants for additional prize symbols of souvenir character as badges for the graduating students and plaques, handed in as prizes.

4.2. Academic prizes. They can be - charters / eulogistic and honorary /badges /honorary and jubilee/, medals /honorary and jubilee/. Notwithstanding at what level and about which educational degree they are handed in, they have two basic purposes - to be honored and distinguished with their success the person, who receives them and to be given opportunity he/she to be able to preserve the memory about his/her activity during the training. Nowadays the prizes, which are handed in are adapted and they can be displayed by being put into a frame /for example/ and to become generally known to everyone, who enter in the office, study of the person, who has received them. This type of acknowledgement is motivating and it is an element of the authority of the university and the person.

4.2.1. The breast signs, medals and badges are an appropriate accessory, which demonstrates affiliations, membership or expression of sympathy towards a certain institution or community. They are a matter of pride for distinguished figures and academic persons, memory about the time of their activity or concrete undertakings and events.

The badge (fig. 8) of the Medical University - Varna is a stylized variant of the logo of the university, out of material, which imitates gilt. Since 2013 it is given at the solemn ceremonies on occasion defence of theses of the graduating students.

${ }^{9}$ Official flagfromUniversity of Economics - Varna and Medical University-Varna ${ }^{9}$ https://www.ue-varna.bgand personal archive (2017) 

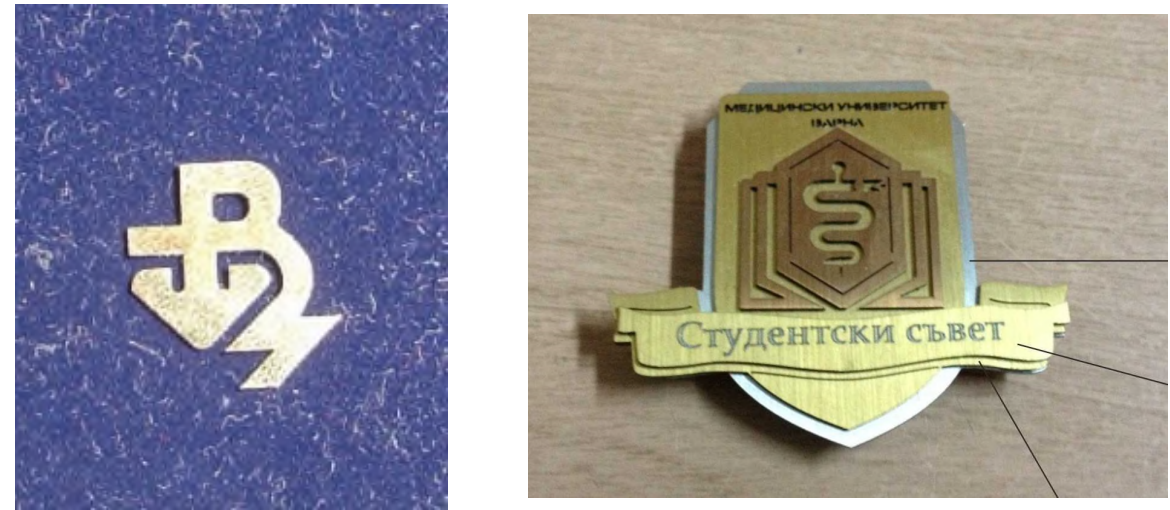

Fig. 8 Badge with a logo from Technical University - Varna and Medical University - Varna ${ }^{10}$

4.2.2. The prize plaque (fig. 9 and 10) can be with full coat of arms by means of several layers of chromium-nickel base, casting, metal, plastic, wood, crystal or other usually with the shape of a circle with an embossed depiction and inscriptions, connected with some event, competition, jubilee, which serves as an honorary sign.

It is put in a luxurious wooden box, allowing its transportation with a view to the visual criteria about style, safety at protection of its integrity. The plaque is with additional elements to the academic regalia in a strengthened strict and individual character, allowing enrichment and diversity towards the concrete event. When designing plaques, it is necessary to take into account the logical and raffic design guidelines. ( Макуейд, 2007 ).
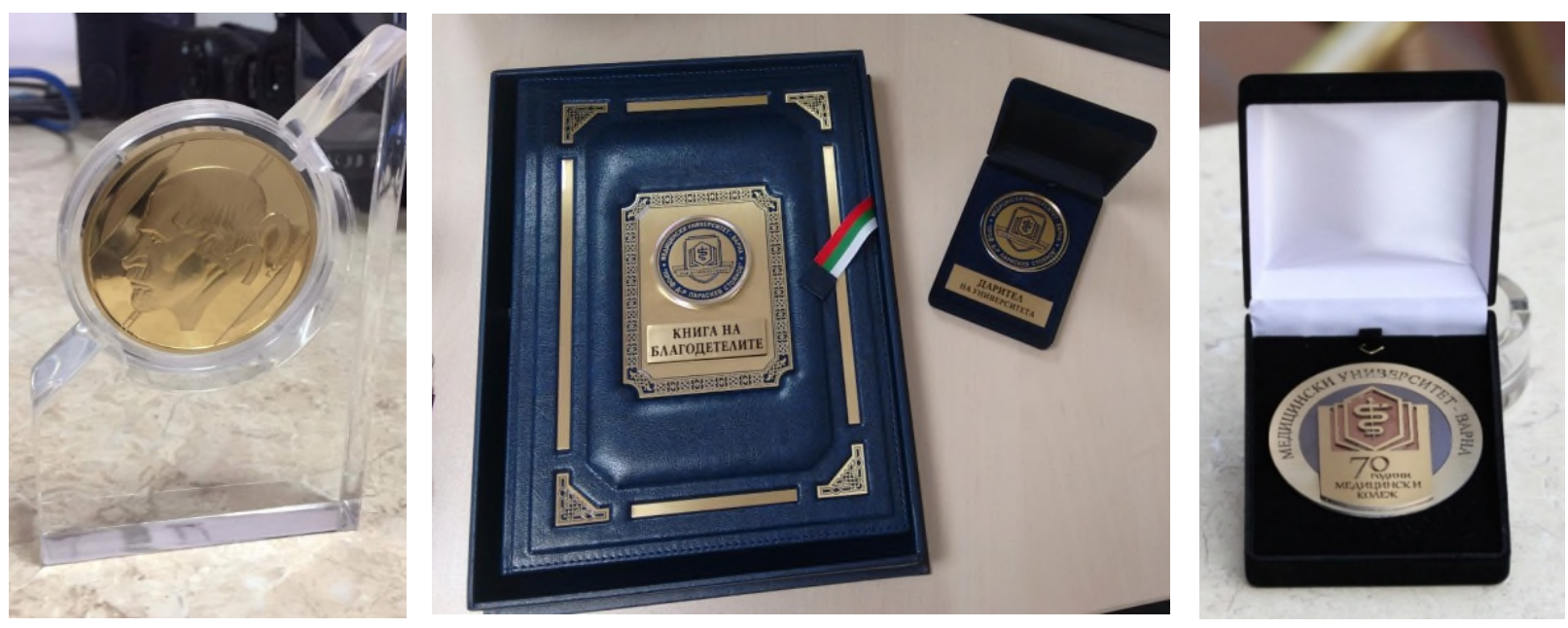

Fig. 9 Prize plaque on the occasion of 55 years Medical University - Varna, Thankful book and plaque and prize plaque on the occasion of 70 years Medical College - Varna ${ }^{11}$

\footnotetext{
${ }^{10}$ Badge with a logo from Technical University - Varna and Medical University - Varna ${ }^{10}$ Personal archive

${ }^{11}$ Prize plaque on the occasion of 55 years Medical University - Varna, Thankful book and plaque and prize plaque on the occasion of 70 years Medical College - Varna ${ }^{11}$ Personal archive
} 


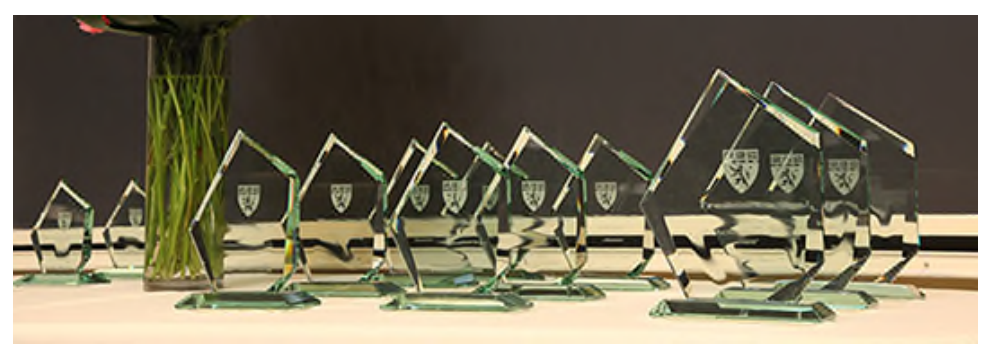

Fig. 10 Prize plaque. University in Harvard ${ }^{12}$

4.3. The academic souvenirs (fig. 11, 12 and 13) are memory for a certain period of the life of each person. The album with photographs of the class and the batch of graduates is always interesting to be opened, to be remembered interesting cases and events. The ring, medallion emphasize affiliations to a certain group, which have graduated at a school or university, famous for its traditions. On the working desk may be put a plaque with the logo of the school/university and the year of graduation/ the batch of graduates.

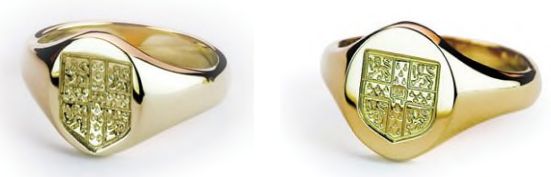

Fig. 11 Rings with engravement -ladies' and gentlemen's ring with a logo. University in Cambridge ${ }^{13}$
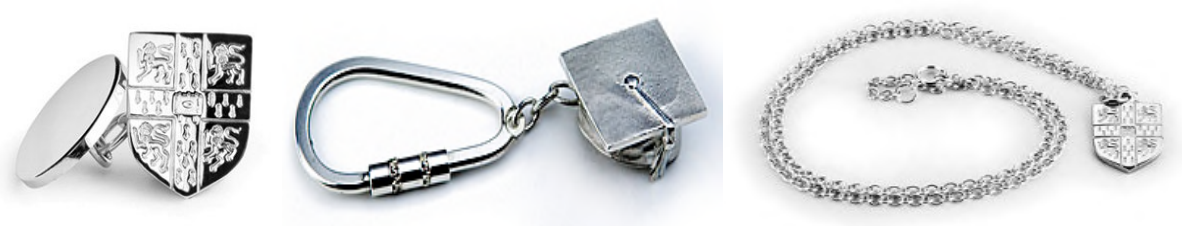

Fig. 12 Souvenirs- medallions, buttonholes, keychains with an engraved logo. University in Cambridge ${ }^{14}$

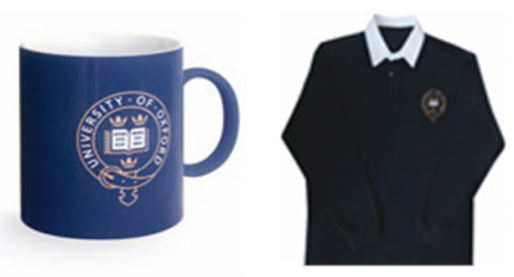

Fig. 13 Souvenirs- cups, sports equipment. University in Oxford ${ }^{15}$

\footnotetext{
${ }^{12}$ Prize plaque. University in Harvard ${ }^{12} \mathrm{https} / / / \mathrm{mfdp} . \mathrm{med}$.harvard.edu/awards (2017)

${ }^{13}$ Rings with a logo. University in Cambridge ${ }^{13} \mathrm{https} / / /$ www.cam.ac.uk/ (2017)

${ }^{14}$ Souvenirs. University in Cambridge ${ }^{14} \mathrm{https}$ ://www.cam.ac.uk/ (2017)

${ }^{15}$ Souvenirs- cups, sports equipment. University in Oxfordhttp://www.ox.ac.uk/about (2017)
} 
As a cultural and spiritual phenomenon, as an intellectual community and a guardian of values the University recreates its own specific symbolic system of academic signs and traditions. They manifest at carrying out of ceremonies, celebrating of festivals /of the school or university, national and local/, the sending off of batches of graduates and handing in of diplomas, certificates and prizes. The place of the school or university in the society, its authority is emphasized through these symbols and their usage at different ceremonies, as well as the type of the concrete prizes and signs.

The necessity of building up of a complete system and design for interdisciplinarity, methodology and standardization in the academic circles, emphasizes more issues, specifying and forming the whole discussed problem: Taking of the initiative for creation of a national discussion as per the topic for the necessity of such a standardization and in other spheres of the state system - law, medicine and etc. or which educational degrees really need the introduction of academic regalia. In this sequence of thoughts it is good to be enclosed examples, which to be analyzed and discussed in order to be estimated the benefit of such a systematization and identification in the academic circles - the uniting of the people in the academic communities, uniting of the team and desire for work as per a joint cause /Alumni club, the sports teams in the universities, the clubs as per interests and etc./

\section{Conclusions}

"Design is not only a process related to machine production, it is a means of promoting values, ideas and opinions, and what things can or should be in accordance with individual, corporate, institutional or national goals." ${ }^{16}$ The contemporary strategy for design of the academic regalia should combine the established traditions in the sociocultural mentality of the Bulgarians with a far-sighted orientation in the future, in order to guarantee a qualitative and lasting art product. It is time the academic communities of the state, as well as of the private universities in Bulgaria, to unite themselves around the idea for standardization in the field of the graphical, visual and ceremonial academic symbolization. As a designer's purpose in this respect is outlined the creation and application of a clear methodology for designing of academic signs on the grounds of a profound theoretical-applied analysis of the principles in design of the academic regalia in one real university. These conclusions are grounded on personal experience in the research, design, perfection and elaboration of the contemporary academic regalia of one of the most prestigious universities in Bulgaria - the Medical University in Varna.

The design of each representing sign begins with the formation of some idea in the author, which passes through different stages until the achievement of the desired result.

In the concrete case are compared the former and the modernized and updated ones: the logo, the Rector's regalia, formal plaques, the printed publications and the formal site of the Medical university - Varna, in one innovative and modern way, as despite this the strive to be preserved the strictness and the representative appearance of the signs, as well as the principles, which they symbolize throughout the years.

The first stage is one of the most important - here originates the initial idea, connected with the complete vision and the first impression, which the created creation (work of art) shall provoke. Here is clarified the basic conception: whether there can be combined some additional functions, which shape would

${ }^{16}$ Charlotte and Fiel, 2001, p.4, Taschen "Design" 
further about the maximum representation and positioning of the sign in environment as an office and study for example. Out of these analyses and decisions originate the first designs, accompanying the solving of the problem.

The building and the following of a methodology furthers the formation and protection of social authority, it contributes for the successful functioning of the educational structure in compliance with the traditions, as well as with the new technologies and scientific achievements, preserves the university as spiritual value, intellectual phenomenon and a state institution.

\section{References:}

Чин, 2007, стр.8, Книгомания “Енциклопедия на цүветовете и материи за обзавеждане на дома"

Фийл, 2006, “Графичен дизайн на 21 век”, Taschen; Алианс-97

Charlotte and Fiel, 2001, p.4, "Design”, Taschen

Лольр, 2006, стр.185, Софтпрес "Дизайн, предпечат и печат"

Лольр, 2006, стр.34, Софтпрес “Дизайн, предпечат и печат”

Макуейд, 2007, стр. 90, Софтпрес "Професионален дизайн на бизнес материали”

Макуейд, 2007, Софтпрес "Професионален дизайн на печатни материали”

\section{Online sources:}

https://en.wikipedia.org/wiki/Academic_dress_of_the_University_of_Oxford (2017)

https://www.color-meanings.com/blue-color-meaning-the-color-blue/ (2017)

http://www.sc.edu/about/index.php (2017)

http://igcbg.com/ (2017)

http://www.cam.ac.uk (2017)

http://www.ue-varna.bg (2017)

https://mfdp.med.harvard.edu/awards (2017)

https://www.cam.ac.uk (2017)

http://www.ox.ac.uk/about (2017)

http://www.mu-varna.bg (2017) 